\title{
PI3K Alteration Positive
}

National Cancer Institute

\section{Source}

National Cancer Institute. PI3K Alteration Positive. NCI Thesaurus. Code C153383.

An indication that mutation, overexpression, fusion or rearrangement of a PI3K family member has been detected in a sample. 